\title{
OTIMIZAÇÃO DO PROCESSAMENTO DE PRODUTOS AGRÍCOLAS: UM ESTUDO NO BENEFICIAMENTO DE CULTIVARES DE CACAU
}

\author{
Diego Castro Fettermann* \\ Ângelo Márcio Oliveira Sant'Anna**
}

RESUMO: Uma das etapas mais importante no processamento de cultivares do cacau é a solidificação do líquor. Esse processo envolve um sistema de resfriamento que proporciona a solidificação do produto. A dificuldade em identificar parâmetros adequados para o ajuste do processo resulta em perda de qualidade do produto no processamento. Este trabalho objetiva otimizar os fatores que influenciam no processamento de cultivares de cacau durante a solidificação do líquor. $\mathrm{O}$ delineamento experimental proposto foi o projeto em blocos aleatórios com parcelas subdivididas (split-plot), arranjo fatorial $2^{3}$ e três réplicas. Dentre os fatores analisados, o tipo de líquor, a vazão da bomba e a velocidade da esteira apresentam influência significativa na temperatura final do processo de solidificação de cultivares de cacau.

PALAVRAS-CHAVE: Arranjo fatorial; Split-plot; Theobroma cacao L.

\section{OPTIMIZATION IN THE PROCESSING OF AGRICULTURAL PRODUCTS: A STUDY ON IMPROVEMENT OF COCOA CULTIVARS}

ABSTRACT: Liquor solidifying is one of the most important stages in the processing of cocoa cultivars. The process involves a cooling system which solidifies the product. Difficulties in the identification of adequate parameters for process adjustment cause loss of the product's quality. Current analysis optimizes the factors that affect cocoa cultivar processing during the solidification of the liquor. Experimental scheme comprised randomized split-plot blocks, a $2^{3}$ factorial scheme and three replications. Liquor type, pump discharge and treadmill speed significantly affect the final temperature within the solidification process of cocoa cultivars.

KEY WORDS: Factorial scheme; Split-plot; Theobroma cacao L.

\footnotetext{
Doutor em Engenharia de Produção, Docente permanente do Programa de Pós-graduação em Engenharia de Produção da Universidade Federal de Santa Catarina (PPGEP/UFSC), Brasil. E-mail: d.fettermann@ufsc.br

** Doutor em Engenharia de Produção, Docente da Escola Politécnica da Universidade Federal da Bahia (UFBA), Brasil.
} 


\section{INTRODUÇÃO}

O cacau ou cacaueiro (Theobroma Cacao L) é uma árvore tropical de clima úmido originária da América Central e do Sul (BELITZ; GROSCH, 1999). Seu cultivo no território brasileiro teve início por volta de 1680, inicialmente na região Norte (COE; COE, 1996) e depois se estendeu para a região Sul da Bahia (CASSANO et al., 2009) e desta para as demais regiões do país (DIAS et al., 2003). Mesmo diante da crise que prejudicou o cultivo do cacau no Brasil durante os anos 1990 (SILVA et al., 2010) e o seu desenvolvimento nos países africanos e na Malásia e Indonésia nos anos 80 e 90 respectivamente, a América do Sul permanece com um volume considerável da produção mundial de cacau (FOLD, 2001). As estimativas de produção de amêndoas de cacau para o período de 2013-2014 indicam uma produção de 210.000 toneladas, correspondendo a 4,8\% da produção mundial (IGCO, 2015).

A produção de cacau oriunda de cultivares em território nacional teve início com o surgimento das primeiras indústrias beneficiadoras do cacau (ALGER; CALDAS, 1994). Na década de 80, com o incentivo estatal e o aumento dos preços do cacau no mercado mundial, esse setor recebeu grandes investimentos e o Brasil passou a ser um dos principais processadores de cacau no mundo (GARCIA, 2003). Empresas multinacionais, como a Cargill, ADM e Barry Callebaut dominam o processamento do cacau no Brasil e no mundo, chegando a processar cerca de $75 \%$ da produção mundial (FOLD, 2001).

O processamento das amêndoas do cacau tem seu início ainda na fazenda, onde, após a colheita, as sementes são removidas dos frutos, amontoadas e cobertas com folhas de bananeira para sofrerem uma fermentação natural, sendo, posteriormente, submetidas a uma secagem. Essa etapa irá garantir a preservação das características físico-químicas, sensoriais e qualitativas, que podem garantir a conservação do sabor e aroma de um chocolate de qualidade. Em seguida, ocorre a moagem dos "nibs", que correspondem às amêndoas de cacau fermentadas e tostadas, para produção dos subprodutos, tais como manteiga de cacau, pó de cacau e líquor do cacau (Figura 1) (BISPO et al., 2005).

O líquor do cacau, um material pastoso, é comercializado de duas formas: a granel, embarcado em caminhões-tanques ou embalado em sacos de papel. O líquor 
do cacau embalado em sacos de papel precisa ser resfriado até atingir o estado sólido. As indústrias de processamento de cacau encontram dificuldade nesta etapa de resfriamento, sendo que este processo é considerado uma restrição ao aumento da produtividade. Além disso, se verifica um volume considerável de perda de produção nesta etapa devido a produtos fora de especificação, mais especificamente o líquor não solidificado. Estas perdas resultam em redução de produtividade e aumento dos custos de produção em razão da necessidade de retrabalho do material.

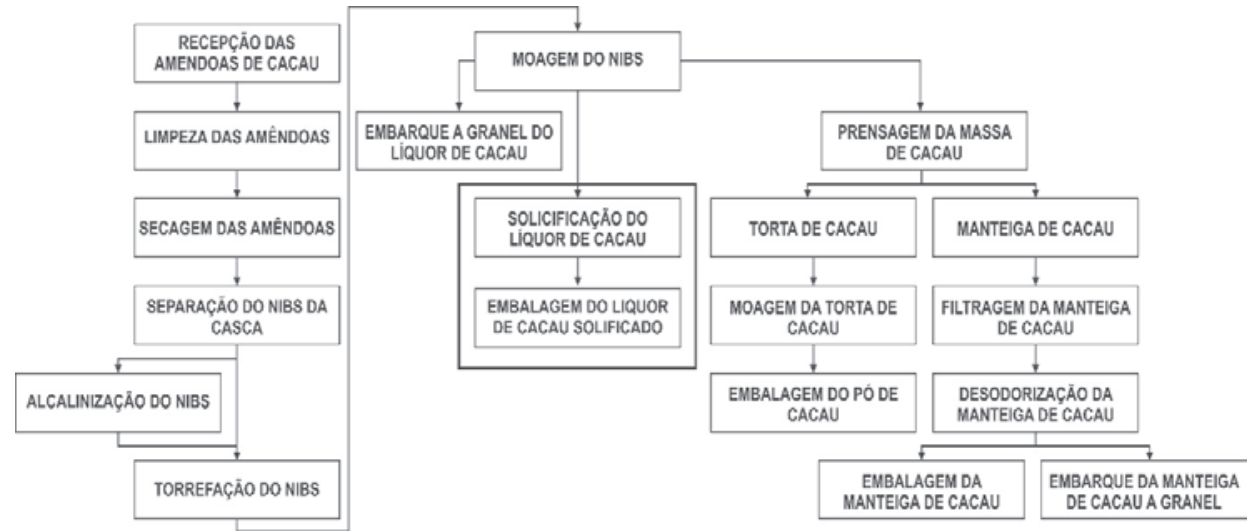

Figura 1. Etapas do processamento de cultivares do cacau

O processo de solidificação é influenciado por diversos fatores os quais ainda podem possuir interações. O efeito final do processo é observado no estado físico do líquor do cacau, representado por sua temperatura final. Devido à complexidade dos efeitos causados por esses fatores e de suas respectivas interações no processo de solidificação do líquor do cacau se verifica a necessidade em analisar o sistema de processamento a fim de estabelecer um padrão de produção com redução do desperdício e maior qualidade no processo produtivo, assim como diversos estudos verificados na área (SILVA et al., 2008; MADRONA et al., 2009). A partir disso, este trabalho tem por objetivo otimizar os fatores que influenciam no processamento de cultivares de cacau durante a solidificação do líquor. Para tanto, foi proposto um delineamento experimental em blocos aletatórios com parcelas subdivididas (split$p l o t$ ), arranjo fatorial $2^{3}$ e três repetições. Um delineamento experimental consiste em uma série de testes em que são avaliados os fatores de um processo a fim de 
observar e identificar as possíveis mudanças na variável de resposta do processo (MONTGOMERY, 2003). Métodos experimentais são amplamente utilizados em pesquisas na área, como avaliar o desempenho de diferentes tipos de semeadura no cultivo de soja (SCHMIDT FILHO et al., 2011) influência da manteiga do cacau no refino por dióxido de carbono (TAN, et al. 2008), identificar níveis adequados de densidade de plantas para o cultivo de cultivares de milho (DOS SANTOS et al., 2011); na qualidade do leite achocolatado (DE CLERCQ, et al., 2012), entre outros. Além disso, estudos sobre a melhoria no processamento de produtos agrícolas são importantes para a melhoria da viabilidade econômica e competitividade das atividades relacionadas ao cultivo (TODISCO et al., 2012; SIMÕES et al., 2014).

\section{MATERIAL E MÉTODOS}

Esta pesquisa experimental foi desenvolvida em uma indústria processadora de cacau, localizada no município de Ilhéus, Bahia, situado nas coordenadas geográficas $14^{\circ}$ 47'20" de latitude Sul e 3902'58” de longitude Oeste, a 52 m de altitude média. Segundo a classificação climática de Köppen-Geiger, o clima da região é úmido com verão quente na faixa $\mathrm{Cfa}$, sendo a temperatura média anual de $24^{\circ} \mathrm{C}$ e a umidade média relativa do ar superior a $80 \%$.

$\mathrm{O}$ processo de solidificação do líquor de cacau ocorre por meio do seu resfriamento em trocadores de calor e de um túnel de solidificação. Uma bomba é responsável por movimentar o líquor de cacau dos tanques até o túnel de solidificação. Nesse processo, o líquor sofre seu primeiro resfriamento por meio de dois trocadores de calor, denominados votators. Esses equipamentos utilizam um resfriamento por água fria $\left(4^{\circ} \mathrm{C}\right)$, que troca calor com a massa de cacau que está em uma temperatura inicial entre $42^{\circ} \mathrm{C}$ e $45^{\circ} \mathrm{C}$. Em seguida, o líquor é encaminhado a uma esteira direcionada ao túnel de resfriamento, com temperatura interior entre $5^{\circ} \mathrm{C}$ e $8^{\circ} \mathrm{C}$. Ao final do túnel de resfriamento, o líquor de cacau deve estar em estado físico sólido a fim de permitir o acondicionamento em embalagens de papel. Entretanto, no caso do líquor não ser suficiente resfriado para atingir o estado sólido este não pode ser embalado e precisa ser novamente processado, resultando perdas no seu processamento. 
No processo de solidificação são processadas duas diferentes especificações de líquor de cacau, de acordo com a sua granulometria oriundos de diferentes cultivares de cacau. As especificações do líquor de cacau são denominadas: natural refinado (refinado) e natural denso (denso).

\subsection{PROCEDIMENTOS EXPERIMENTAIS}

As informações sobre os fatores que influenciam o sistema de processamento do produto foram coletadas com a equipe de operadores envolvidos no sistema produtivo. A principal preocupação dos operadores está relacionada ao estado físico do produto final, aspecto de qualidade no qual o produto deve estar completamente solidificado. Foi observada a dificuldade dos operadores em determinar os ajustes dos fatores do processo, sendo que, cada operador, de acordo com sua experiência, possui diferentes medidas de ajustes dos fatores para a solidificação do líquor do cacau.

Os operadores identificaram sete diferentes fatores que poderiam influenciar no desempenho do processo: (i) tipo de líquor do cacau; (ii) temperatura do líquor no início do processo; (iii) vazão da bomba; (iv) temperatura da água nos votators; (v) abertura dos bicos de alimentação; (vi) velocidade da esteira e (vii) temperatura interna do túnel. Dentre estes fatores, foram considerados como sendo fatores de ruído: (i) temperatura do líquor nos votators; (ii) temperatura da água nos votators; (iii) abertura dos bicos injetores e (iv) temperatura interna do túnel, em virtude da impossibilidade de alterar os valores dos níveis destes fatores durante o processamento. Assim, foram selecionados os três fatores para serem analisados no experimento:

- Tipo de cacau: líquor de cacau natural refinado e o líquor de cacau natural denso. Atualmente não existe diferença entre os tratamentos para os diferentes tipos de cacau. É esperado pelos profissionais que este fator possa afetar o processo de solidificação, assim como interagir com os demais.

- Vazão da bomba: $45 \%$ e $60 \%$ da potência aplicada no motor da bomba. 
Caso a vazão da bomba seja elevada pode ocorrer aumento na pressão da linha de líquor, entupimento dos bicos injetores, além de superar a capacidade de resfriamento do processo.

- Velocidade da esteira: $80 \%$ e $100 \%$ da potência aplicada no motor da esteira. Caso a velocidade da esteira do túnel seja elevada, o tempo de passagem do líquor de cacau pelo túnel de resfriamento não será suficiente para solidificar o líquor.

A variável resposta a ser quantificada durante o experimento é o estado físico "sólido" do líquor de cacau, mensurado a partir da temperatura do produto na saída do túnel de solidificação. O instrumento recomendado para a mensuração da temperatura é o termômetro Estanque, que utiliza um sistema de medição em conformidade com a norma EN 13485 (European Standards). O líquor de cacau resfriado a temperatura igual a $25^{\circ} \mathrm{C}$ alcançará seu estado sólido. Entretanto um resfriamento inferior a esta temperatura resultará em redução da capacidade de produção, enquanto que uma temperatura do líquor de cacau superior a $25^{\circ} \mathrm{C}$ resulta em produtos não sólidos e classificados como 'não conforme'.

\subsection{PROCEDIMENTOS ESTATÍSTICOS}

O sistema de processamento de cultivares de cacau estudado apresenta alta complexidade quanto ao tempo de ajustes e alterações dos equipamentos conforme $o$ tipo de líquor de cacau processado durante a produção de grandes lotes (bateladas). A produção de um tipo de líquor pode ocorrer durante semanas. Em razão disto, a aleatorização dos diferentes tipos de líquor de cacau analisados no experimento é inviável pela impossibilidade de troca de matéria-prima, do volume de produção e do custo. Assim, foi escolhido um projeto experimental robusto denominado delineamento experimental em blocos aleatórios com parcelas subdivididas (splitplot) em arranjo fatorial $2^{3}$.

Este tipo de projeto experimental contempla realizar testes com cada uma das combinações do arranjo experimental $2^{3}$, sendo três fatores (tipo de líquor, vazão e velocidade) a dois níveis cada, o que resulta em um bloco de oito ensaios 
experimentais. Os blocos aleatorizados foram replicados três vezes, para uma melhor precisão dos resultados, gerando um total de 24 experimentos. Foram estimados os percentuais de importância e os coeficientes de influência dos fatores nas médias das temperaturas finais no processo de solidificação do líquor. As análises estatísticas foram realizadas no programa Minitab $16^{\circledR}$ (MINITAB, 2003).

\section{RESULTADOS E DISCUSSÃO}

A coleta de dados foi realizada nos dias 23/09/2014 para o primeiro bloco (líquor natural refinado), e 30/09/2014 para o segundo bloco (líquor natural denso). Para a execução do experimento, todo o sistema de processamento foi monitorado para que não ocorressem erros experimentais e os fatores considerados como ruído foram controlados, sendo: (i) a temperatura do líquor nos votators na faixa de $43^{\circ} \mathrm{C}$ a $45^{\circ} \mathrm{C}$; (ii) a temperatura da água nos votators em $27^{\circ} \mathrm{C}$; (iii) a abertura dos bicos injetores em 5atm; e (iv) a temperatura interna do túnel na faixa de $4^{\circ} \mathrm{C} \mathrm{a} 6^{\circ} \mathrm{C}$. $\mathrm{Na}$ Tabela 1 são apresentadas as medições do projeto experimental para coleta de dados, com a ordem aleatorizada dos ensaios por blocos.

Tabela 1. Projeto experimental para coleta de dados

(continua)

\begin{tabular}{cccccc}
\hline \multicolumn{5}{c}{ Fatores controláveis } & Variável resposta \\
\hline Ordem & Blocos & Tipo & Velocidade & Vazão & Temp. Final \\
\hline 1 & 1 & $\begin{array}{c}\text { Refinado } \\
(-1)_{-}\end{array}$ & $80 \%(-1)$ & $60 \%(+1)$ & $25,00{ }^{\circ} \mathrm{C}$ \\
2 & 1 & Refinado (-1) & $100 \%(+1)$ & $45 \%(-1)$ & $24,40{ }^{\circ} \mathrm{C}$ \\
3 & 1 & Refinado (-1) & $80 \%(-1)$ & $45 \%(-1)$ & $24,10{ }^{\circ} \mathrm{C}$ \\
4 & 1 & Refinado (-1) & $100 \%(+1)$ & $60 \%(+1)$ & $25,20{ }^{\circ} \mathrm{C}$ \\
5 & 2 & Denso (+1) & $80 \%(-1)$ & $60 \%(+1)$ & $24,50{ }^{\circ} \mathrm{C}$ \\
6 & 2 & Denso (+1) & $100 \%(+1)$ & $60 \%(+1)$ & $25,00{ }^{\circ} \mathrm{C}$ \\
7 & 2 & Denso (+1) & $80 \%(-1)$ & $45 \%(-1)$ & $24,60{ }^{\circ} \mathrm{C}$ \\
\hline
\end{tabular}


(conclusão)

\begin{tabular}{cccccc}
\hline \multicolumn{5}{c}{ Fatores controláveis } & Variável resposta \\
\hline Ordem & Blocos & Tipo & Velocidade & Vazão & Temp. Final \\
\hline 8 & 2 & Denso (+1) & $100 \%(+1)$ & $45 \%(-1)$ & $24,90{ }^{\circ} \mathrm{C}$ \\
9 & 3 & Refinado (-1) & $80 \%(-1)$ & $60 \%(+1)$ & $24,90{ }^{\circ} \mathrm{C}$ \\
10 & 3 & Refinado (-1) & $80 \%(-1)$ & $45 \%(-1)$ & $24,60{ }^{\circ} \mathrm{C}$ \\
11 & 3 & Refinado (-1) & $100 \%(+1)$ & $45 \%(-1)$ & $24,30{ }^{\circ} \mathrm{C}$ \\
12 & 3 & Refinado (-1) & $100 \%(+1)$ & $60 \%(+1)$ & $25,30{ }^{\circ} \mathrm{C}$ \\
13 & 4 & Denso (+1) & $100 \%(+1)$ & $45 \%(-1)$ & $25,00{ }^{\circ} \mathrm{C}$ \\
14 & 4 & Denso (+1) & $80 \%(-1)$ & $60 \%(+1)$ & $24,70{ }^{\circ} \mathrm{C}$ \\
15 & 4 & Denso (+1) & $80 \%(-1)$ & $45 \%(-1)$ & $24,70{ }^{\circ} \mathrm{C}$ \\
16 & 4 & Denso (+1) & $100 \%(+1)$ & $60 \%(+1)$ & $25,10{ }^{\circ} \mathrm{C}$ \\
17 & 5 & Refinado (-1) & $80 \%(-1)$ & $60 \%(+1)$ & $24,70{ }^{\circ} \mathrm{C}$ \\
18 & 5 & Refinado (-1) & $100 \%(+1)$ & $45 \%(-1)$ & $24,80{ }^{\circ} \mathrm{C}$ \\
19 & 5 & Refinado (-1) & $100 \%(+1)$ & $60 \%(+1)$ & $25,10{ }^{\circ} \mathrm{C}$ \\
20 & 5 & Refinado (-1) & $80 \%(-1)$ & $45 \%(-1)$ & $24,30{ }^{\circ} \mathrm{C}$ \\
21 & 6 & Denso (+1) & $100 \%(+1)$ & $60 \%(+1)$ & $25,20{ }^{\circ} \mathrm{C}$ \\
22 & 6 & Denso (+1) & $80 \%(-1)$ & $45 \%(-1)$ & $24,40{ }^{\circ} \mathrm{C}$ \\
23 & 6 & Denso (+1) & $100 \%(+1)$ & $45 \%(-1)$ & $24,60{ }^{\circ} \mathrm{C}$ \\
24 & 6 & Denso (+1) & $80 \%(-1)$ & $60 \%(+1)$ & $24,50{ }^{\circ} \mathrm{C}$ \\
\hline
\end{tabular}

Fonte: Autores

Podemos observar na análise de variância (Anova) que os fatores velocidade, vazão e a interação tipo x vazão são estatisticamente significativos (valor- $p<0,01$ ), demonstrando efeito na temperatura final do líquor. Entretanto, o efeito do tipo do líquor não foi significativo na temperatura final (valor- $p=0,557$ ), conforme Tabela 2. 
Tabela 2. Análise de variância do delineamento fatorial

\begin{tabular}{lccccc}
\hline Fonte & gl & $\begin{array}{c}\text { Soma } \\
\text { quadrada }\end{array}$ & $\begin{array}{c}\text { Média } \\
\text { quadrada }\end{array}$ & Teste F & Valor $P$ \\
\hline Tipo & 1 & 0,01042 & 0,01042 & 0,41 & $0,557^{\mathrm{ns}}$ \\
Blocos & 4 & 0,10167 & 0,02541 & 0,74 & $0,582^{\mathrm{ns}}$ \\
Velocidade & 1 & 0,63375 & 0,63375 & 18,47 & $0,001^{* *}$ \\
Vazão & 1 & 0,84375 & 0,84375 & 24,60 & $0,000^{* *}$ \\
Tipo*velocidade & 1 & 0,03375 & 0,03375 & 0,98 & $0,341^{\mathrm{ns}}$ \\
Tipo*vazão & 1 & 0,35042 & 0,35042 & 10,21 & $0,008^{* *}$ \\
Velocidade*vazão & 1 & 0,07042 & 0,07042 & 2,05 & $0,177^{\mathrm{ns}}$ \\
Tipo*Velocidade*vazão & 1 & 0,00375 & 0,00375 & 0,11 & $0,747^{\mathrm{ns}}$ \\
Erro & 12 & 0,41167 & 0,03430 & - & - \\
Total & 23 & 2,45958 & - & - & - \\
\hline
\end{tabular}

* Significativo a 5\% / ** Significativo a 1\% / ${ }^{\text {ns }}$ Não significativo

O resultado encontrado diverge das suposições dos operadores do processo. Estes operadores sugeriam que a densidade do líquor (refinado ou denso) possuía efeito no processo de solidificação. Na Figura 2 são apresentadas as temperaturas médias dos fatores analisados. Este resultado indica que existe uma alteração da temperatura final quando alterados os níveis dos fatores velocidade e vazão, corroborando com os resultados da análise de variância (Tabela 2). Como a velocidade da esteira em um nível menor aumenta o tempo de permanência do líquor de cacau dentro do túnel de resfriamento (votators), a matéria-prima (cacau) é exposta a uma baixa temperatura por mais tempo, resultando em menor temperatura final e maior solidificação do cacau. 


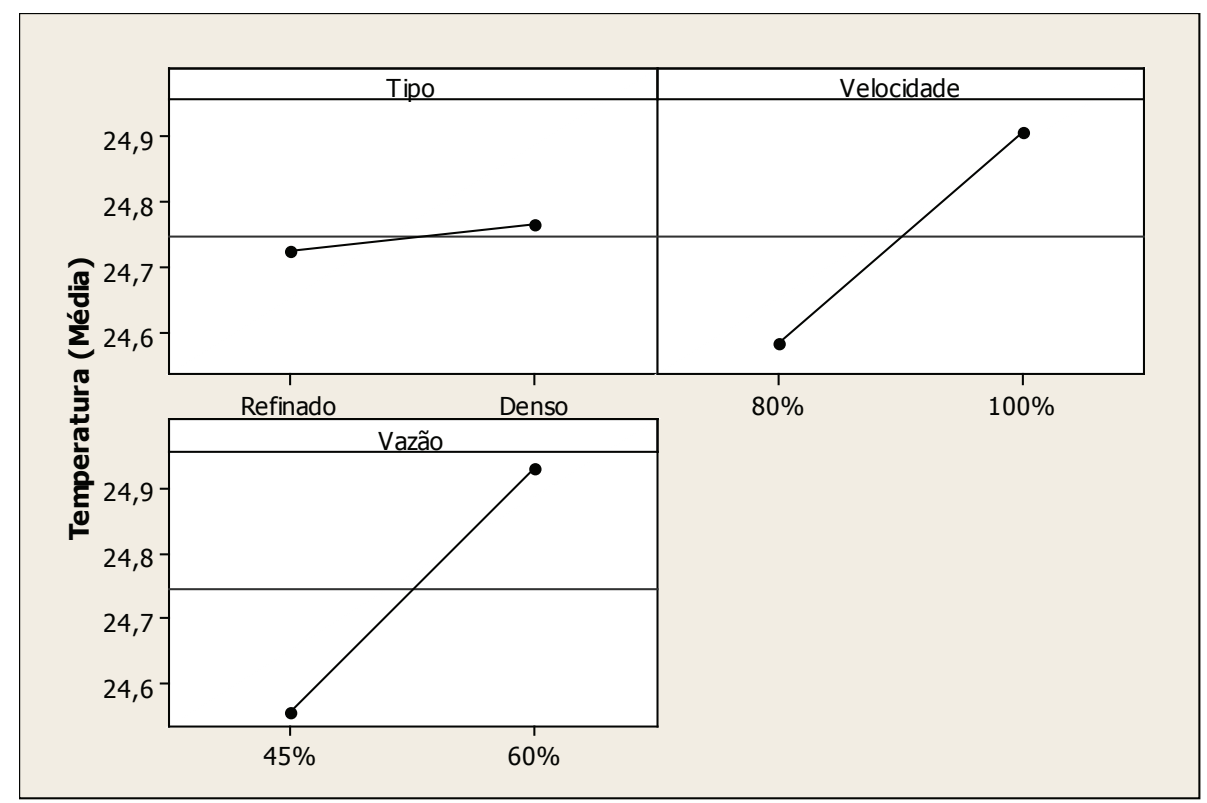

Figura 2. Gráfico das temperaturas médias por fatores Fonte: Minitab ${ }^{\circledR}$

Os resultados da análise de variância (Tabela 2) indicam que a interação entre os fatores tipo de líquor $x$ vazão é significativa ao nível de $5 \%$ (valor- $p=0,008$ ). Apesar de o fator tipo de líquor não afetar diretamente a temperatura final do líquor, sua interação com o fator vazão é significativa. Com um nível menor de vazão a temperatura final do líquor refinado é menor do que a do líquor denso, porém quando a vazão é alterada para um nível maior a temperatura do líquor refinado torna-se maior que a temperatura do líquor denso. Observa-se que à medida que a vazão aumenta, há maior quantidade de produto no interior do túnel de resfriamento, consequentemente, a temperatura do líquor será alta devido a menor troca de calor. A interação entre os demais fatores não apresentou significância estatística: tipo de líquor $x$ velocidade (valor- $p=0,341$ ), velocidade $x$ vazão (valor $p=0,177$ ) e tipo $x$ velocidade $x$ vazão (valor- $p=0,747$ ). Na Figura 3 é ilustrado o percentual de importância e o grau de influência dos fatores analisados no experimento. Os fatores vazão e velocidade apresenta grau de influência positiva 4,95 e 4,25, respectivamente e a interação tipo $x$ vazão apresenta influência negativa $-3,20$ para a solidificação de cultivares de cacau. 


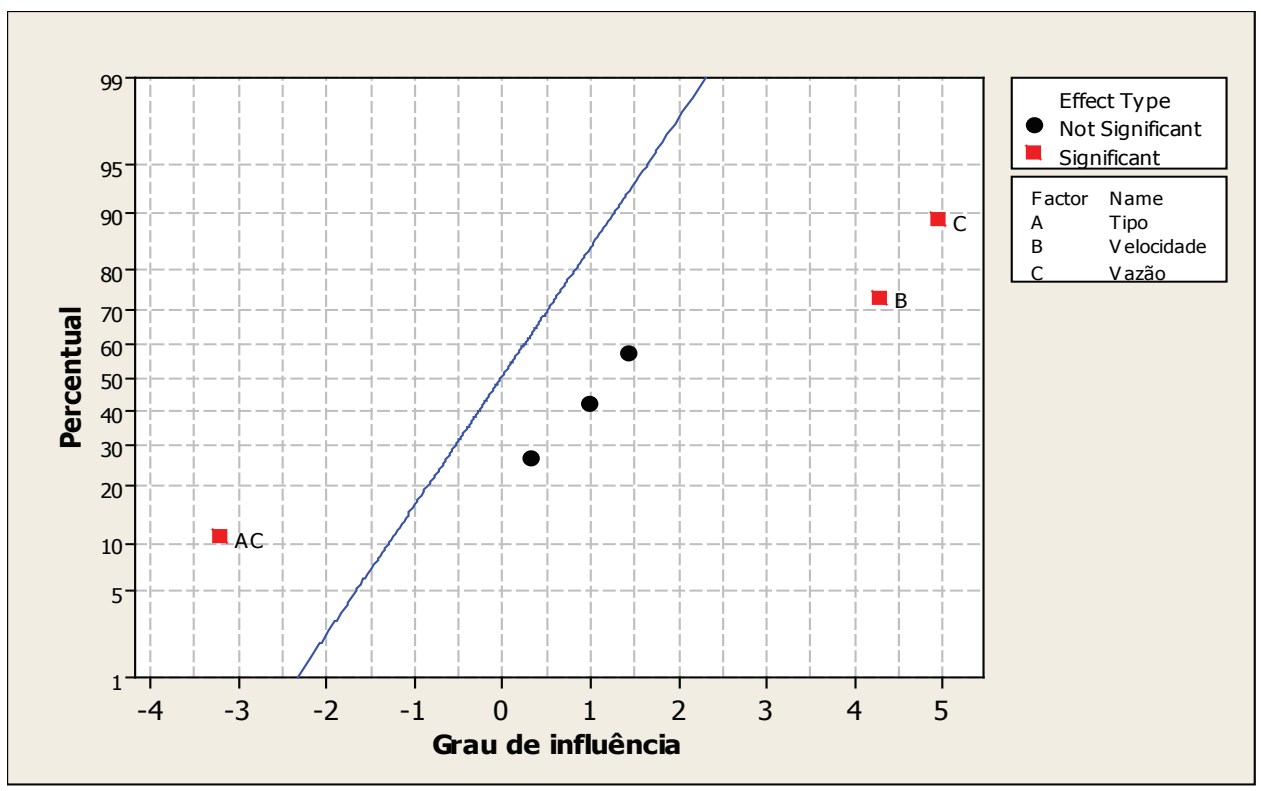

Figura 3. Gráfico de probabilidade normal do grau de influência dos fatores Fonte: Minitab ${ }^{\circledR}$

A equação de regressão do modelo desenvolvido a partir da análise indica um coeficiente de determinação de 0,8246 , valor que representa que a equação possui a capacidade de indicar $82,46 \%$ da variabilidade presente na temperatura final do processo de resfriamento do líquor de cacau. Esse resultado indica que partir da substituição dos coeficientes da equação (fatores controláveis) é possível ter uma satisfatória previsão da temperatura final do líquor de cacau após seu resfriamento. Os coeficientes das variáveis e seu efeito na temperatura final do líquor são apresentados na Tabela 3.

Tabela 3. Coeficientes do modelo de regressão

(continua)

\begin{tabular}{lcccc}
\hline Variável & Efeito & Coeficiente & valor T & valor $\mathbf{p}$ \\
\hline Constante & - & 24,754 & 760,41 & 0,000 \\
Tipo de cacau & 0,041 & 0,020 & 0,64 & 0,557 \\
Velocidade & 0,325 & 0,162 & 4,30 & 0,001
\end{tabular}


(conclusão)

\begin{tabular}{lcccc}
\hline Variável & Efeito & Coeficiente & valor T & valor $\mathbf{p}$ \\
\hline Vazão & 0,375 & 0,187 & 4,96 & 0,000 \\
Tipo de cacau*velocidade & 0,075 & 0,037 & 0,99 & 0,341 \\
Tipo de cacau *vazão & $-0,241$ & $-0,120$ & $-3,20$ & 0,008 \\
Velocidade*vazão & 0,108 & 0,054 & 1,43 & 0,177 \\
Tipo de cacau *velocidade* vazão & 0,025 & 0,012 & 0,33 & 0,747 \\
\hline
\end{tabular}

A partir da substituição dos valores dos coeficientes dos fatores controláveis no experimento (tipo de cacau, velocidade da esteira e vazão da bomba) é possível estimar a temperatura final do líquor de cacau no final do processo de resfriamento. Para o cacau do tipo refinado, todos os fatores em níveis altos atingem uma temperatura do líquor ao final do processo de $25,66^{\circ} \mathrm{C}$, acima dos $25^{\circ} \mathrm{C}$ recomendados pelo processo. Para o cacau do tipo denso, todos os fatores nos seus níveis mais altos indica uma temperatura final do líquor de $25,46^{\circ} \mathrm{C}$. A temperatura final do líquor de cacau do tipo denso nesse arranjo é resultado da interação entre o tipo de cacau e a vazão da bomba (valor-p=0,008). Dessa forma, para ambos os tipos de líquor, o arranjo dos fatores em seus níveis superiores excede a temperatura máxima exigida para a solidificação do líquor de cacau ao final do processo de resfriamento. Para o líquor de cacau do tipo refinado, os resultados indicam que utilizar pelo menos um dos demais fatores em seu nível baixo. A velocidade da esteira em um nível mais baixo (80\%) estima uma temperatura final do líquor de cacau refinado de $24,99^{\circ} \mathrm{C}$. Para a bomba em seu nível mais baixo (45\%) o resultado indica uma temperatura final de $24,26^{\circ} \mathrm{C}$. Para o líquor de cacau do tipo denso, os resultados da equação de regressão também indicam a necessidade de utilizar pelo menos um dos fatores em seu nível mais baixo. Utilizando o nível baixo da velocidade da esteira (80\%), a temperatura final estimada para o líquor do cacau denso ao final do processo é de $24,39^{\circ} \mathrm{C}$ e utilizando o baixo nível da vazão da bomba (45\%) a temperatura estimada é de $24,98^{\circ} \mathrm{C}$.

O resultado obtido permite ao gerente de processo da empresa maior conhecimento sobre o processo. Algumas das premissas dos colaboradores foram confirmadas enquanto outras não. A metodologia científica aplicada forneceu 
fundamentos relevantes para a quebra de paradigmas e de opiniões baseadas em suposições. O conhecimento sobre o efeito dos fatores que afetam o processo permite a empresa realizar as combinações de vazão da bomba e velocidade da esteira de acordo com o tipo de líquor de cacau a ser processado de modo a obter maior volume de produção mantendo os requisitos de qualidade.

\section{CONSIDERAÇÕES FINAIS}

A identificação de níveis ótimos dos fatores de produção permite reduzir a quantidade de desperdícios no processo de beneficiamento e melhoria da competitividade. Este artigo teve por objetivo otimizar os fatores que influenciam no processamento de cultivares de cacau durante a solidificação do líquor do cacau. A partir do experimento realizado, os resultados indicam que o tipo de líquor de cacau (refinado ou denso) não apresenta diferença significativa quanto à temperatura final do processo de solidificação do líquor. Foi identificada interação entre o tipo de líquor do cacau e a vazão da bomba (valor- $p=0,008$ ), indicando que níveis superiores de vazão aumentam mais a temperatura do tipo de líquor refinado que do tipo denso. Os fatores vazão da bomba e velocidade da esteira de resfriamento foram identificados como os mais determinantes para a temperatura final do líquor de cacau ao final do processo de resfriamento. O tipo de experimento split-plot proposto permitiu identificar os níveis adequados de cada um dos fatores investigados que afetam a solidificação do líquor de cacau, bem como conhecer melhor os fatores que compõem o sistema de processamento.

\section{REFERÊNCIAS}

BELITZ, H. D.; GROSCH. W. Food chemistry. 2. ed. Berlin: Springer Verlag, 1999,

BISPO, E. S.; FERREIRA, V.L.P.; SANTANA, L.R.R.; YOTSUYANAGI, K. Sensory profile and acceptance of alkalinized cocoa (Theobroma cacao L,) powder. Food Science and Technology, Campinas, v. 25, n. 2, p.375-381, 2005. 
DE CLERCQ, N.; MOENS, K.; DEPYPERE, F.; AYALA, J. V.; CALLIAUW, G.; DE GREYT, $\mathrm{W}$. Influence of cocoa butter refining on the quality of milk chocolate. Journal of Food Engineering, Oxford, v.111, n. 2, p.412-419, 2012.

DIAS, L. A. S.; SOUZA, C. A. S.; AUGUSTO, S. G.; SIQUEIRA, P. R.; MÜLLER, M. W. Período mínimo de colheita para avaliação de cultivares de cacau em LinharesES. Revista Árvore, Santa Maria, v.27, n.4, p.495-501, 2003. DOI: 10.1590/S010067622003000400010

DOS SANTOS, R.; PAZINI, C. J.; DE OLIVEIRA, R. C. Produtividade de milho sob diferentes densidades populacionais. Revista em Agronegócio e Meio Ambiente, v. 4, n. 3, 2011.

FOLD, N. Restructuring of the European chocolate industry and its impact on cocoa production in West Africa. Journal of Economic Geography, Oxford, v.1, n.4, p.405-420, 2001. DOI: 10.1093/jeg/1.4.405.

GARCIA, A. E. B; LUCAS. V. Inovação Tecnológica e Competitividade na Indústria de Chocolates, Balas e Confeitos. Campinas: ITAL/CEREAL CHOCOTEC, 2000.

ICCO - INTERNATIONAL COCOA ORGANIZATION. Quarterly Bulletin of Cocoa Statistics-Cocoa year 2013/14. London, v, 40, n. 3, 2014. Disponível em: < http:// www,icco,org/about-us/international-cocoa-agreements/cat_view/30-relateddocuments/46-statistics-production,html > . Acesso em: 06 jan. 2015.

MADRONA, G. S.; PIOLA, M. M.; TERRA, C. O. Qualidade em Laticínios: Análise do Conhecimento de Colaboradores de um Pequeno Laticínio Sobre o Assunto. Revista em Agronegócio e Meio Ambiente, v. 2, n. 3, p. 477-486, 2009.

MINITAB Inc. Minitab for Windows 16 user's guide. $4^{\text {th }}$. Ohio: Minitab, 2003.

MONTGOMERY, D. C. Design and analysis of experiments. $5^{\text {th }}$. New York: Jonh Wiley, 2003.

NAGAI, S. Dinâmica concorrencial da cadeia de produção agro-industrial do chocolate cobertura: panorama atual e suas perspectivas futuras. 1997. 167f. 
Dissertação (Mestrado em Engenharia de Produção) - Centro de Ciências Exatas e de Tecnologia, Universidade Federal de São Carlos, São Carlos, 1997.

SCHMIDT FILHO, E.; MORTARI NETTO, R. M.; MAUAD, J. M.; FIGUEIREDO, R., CARMINATTI, J. Comparação entre a Semeadura Convencional e em Grupos e de Doses Crescentes de Potássio em Cobertura sobre a Produtividade da Soja (Glycine $\max$ L.). Revista em Agronegócio e Meio Ambiente, v. 5, n. 1, 2011.

SILVA, V. A.; PEREIRA, R. G. F. A.; BORÉM, F. M.; FERREIRA, D. F. Qualidade do café produzido em diferentes altitudes do Sul de Minas Gerais e processado por via seca. Revista em Agronegócio e Meio Ambiente, v.1, n.2, p. 219-229, 2008.

SIMÕES, D.; FENNER, P. T.; ESPERANCINI, M. S. T. Produtividade e custos do FellerBuncher e processador florestal em povoamento de eucalipto de primeiro Corte. Ciência Florestal, v. 24, n. 3, p. 621-630, 2014. DOI: 10,5902/1980509815742.

TANG, T. J.; JINAP, S.; KUSNADI, A. E.; HAMID, N. S. A. Extraction of cocoa butter by supercritical carbon dioxide: optimization of operating conditions and effect of particle size. Journal of Food Lipids, Malden, v.15, n.2, p. 263-276, 2008, DOI: 10,1111/j,1745-4522,2008,00119.

TODISCO, K. M.; CLEMENTE, E.; ROSA, C. I. L. Franco. Conservação e Qualidade Pós-Colheita de Laranjas "Folha Murcha" Armazenadas em Duas Temperaturas. Revista em Agronegócio e Meio Ambiente, v. 5, n. 3, 2012.

Recebido em: 10 de março de 2016 Aceito em: 29 de agosto de 2016 